\title{
Urinary Ascites: An Uncommon Cause of Sudden Onset Ascites in A Healthy Individual
}

\author{
Lorance Peter ${ }^{1}$ and Jayanta Paul ${ }^{2 *}$ \\ ${ }^{1}$ Columia Asia Hospital, India \\ ${ }^{2}$ Divine Nursing Home, India
}

Submission: August 21, 2017; Published: September 20, 2018

*Corresponding author: Jayanta Paul, Divine Nursing Home, Kolkata, India, Email: dr.jayantapaul@gmail.com

\begin{abstract}
Urinary ascites is a rare condition associated with intra-peritoneal urinary bladder perforation. A middle-aged woman was presented with sudden onset abdominal pain, ascites and decreased urine output. Evaluation revealed mild hepatomegaly, elevated serum creatinine, and hematuria. Ascitic fluid analysis showed high creatinine value suggesting urinary ascites. CT cystography confirmed bladder rupture. This case report highlights that in case of sudden onset ascites, abdominal pain, oliguria and biochemical features of acute renal failure, urinary bladder rupture should be considered in differential diagnosis.
\end{abstract}

\section{Case Report}

39 years old non-alcoholic, non-diabetic lady who was on oral contraceptive pill, was admitted with sudden onset of abdominal swelling, diffuse abdominal pain, and decreased urine output of 24 hours duration. She had no history of fever, vomiting, breathlessness, facial swelling, leg swelling and altered bowel habit. She had a cesarean delivery 12 years back but no history of cardiac, renal and liver diseases. On admission, she was hemodynamically stable, conscious, alert, co-operative, pulse rate: 92/min, blood pressure: 140/86mmHg. On physical examination, there was no anemia, cyanosis, clubbing, jaundice, pedal edema and raised jugular venous pressure. On abdominal examination, she had mild hepatomegaly and but no splenomegaly and signs of chronic liver failure moreover respiratory system and cardiovascular system were normal. Initially she was treated in local hospital and diagnosed with urinary tract infection with acute kidney injury in view of elevated serum creatinine, numerous pus cells in urine and decreased urine output and referred to our hospital for further evaluation.

After history and physical examination, the differential diagnosis was pancreatic ascites, Budd chiari syndrome, Urinary ascites, and acute kidney injury with urinary tract infection.

On the day of admission, laboratory examinations of blood showed total leukocyte count: 13240/cu.mm, hemoglobin: $14.5 \mathrm{~g} / \mathrm{dl}$, platelet count: 170000 /cu.mm, neutrophils: $84.6 \%$, liver function test: normal, serum creatinine: $1.7 \mathrm{mg} / \mathrm{dl}, \mathrm{Na}+$ $137 \mathrm{mmol} / \mathrm{l} \& \mathrm{k+:} 4 \mathrm{mmol} / \mathrm{l}$, amylase: 45U/L, Lipase: 26U/L. Ascitic fluid study showed total protein: $0.6 \mathrm{gm} / \mathrm{dl}$, albumin: 0.3 gm/dl, amylase: $59 \mathrm{IU} / \mathrm{ml}$, creatinine: $2.7 \mathrm{gm} / \mathrm{dl}$, SAAG (serum ascites albumen gradient): 3, leucocyte count: 860.0 cells/ cu.mm, neutrophil 40\%, lymphocyte $60 \%$, RBC count 25Cells/ cu.mm. Routine urine examination showed pus cells: 20-30/ hpf, RBC: $40 /$ hpf, epithelial cells: $2-4 /$ hpf, casts: nil, crystals: nil. Blood and urine culture reports revealed no growth of organism.

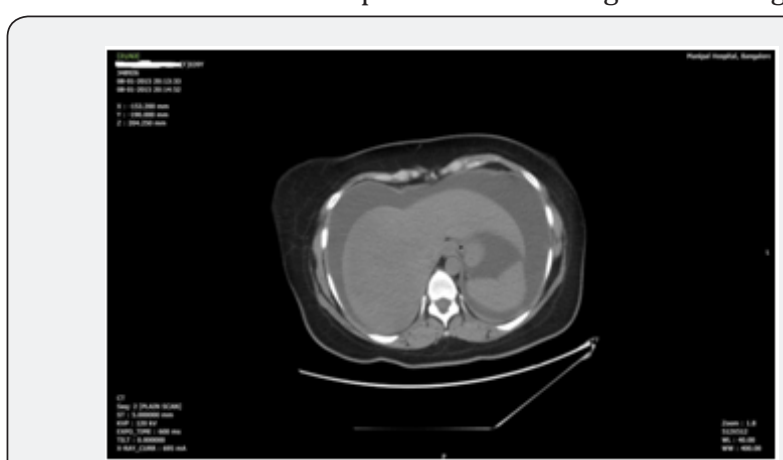

Figure 1: CT scan abdomen showed ascites with normal liver.

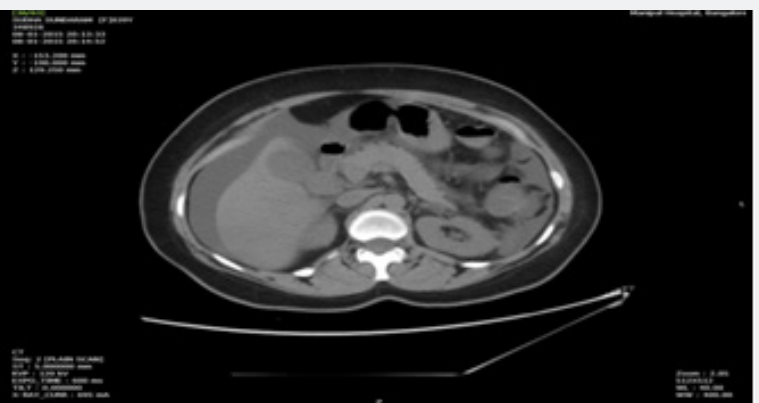

Figure 2:CT scan abdomen showed ascites with normal Pancreas. 
$\mathrm{X}$ ray chest was normal. Trans-abdominal ultrasonography with Doppler revealed significant free fluid in the abdomen, normal renal parenchyma, normal liver morphology, normal portal vein, hepatic vein and inferior vena cava, no pleural effusion. CT scan of abdomen showed as cites but liver architecture was normal (Figure 1-3).

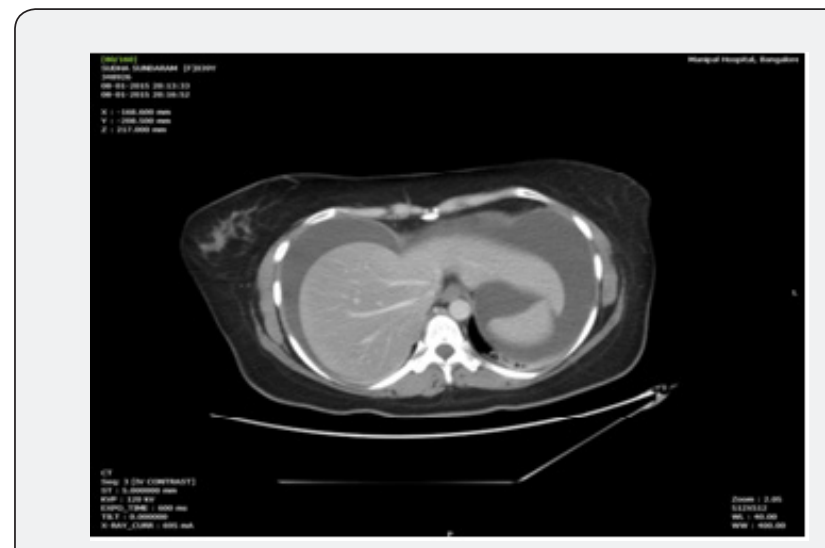

Figure 3:CT abdomen showed normal hepatic veins.

Echocardiography showed ejection fraction: 65\%, normal cardiac chambers, normal cardiac valves, no cardiac wall hyporkinesia.

After thorough evaluation of above reported symptoms and investigations, it was found that patient had sudden onset ascites, oliguria, pain abdomen, hematuria, elevated ascites fluid creatinine level which was greater than serum creatinine level and leukocytosis. So, the provisional diagnosis was urinary ascites. To confirm the diagnosis of urinary ascites, CT cystography (Figure 2) was done which revealed $1.7 \mathrm{~cm}$ defect in the posterior wall of urinary bladder with extravasation of contrast outside the urinary bladder and Cystoscopy revealed thinned bladder wall posteriorly with $1.5 \mathrm{~cm}$ defect in bladder wall.

After Foley's catheterization, ascites was reduced. Then patient was treated with laparoscopic repair of bladder wall defect (Figure 4-6).

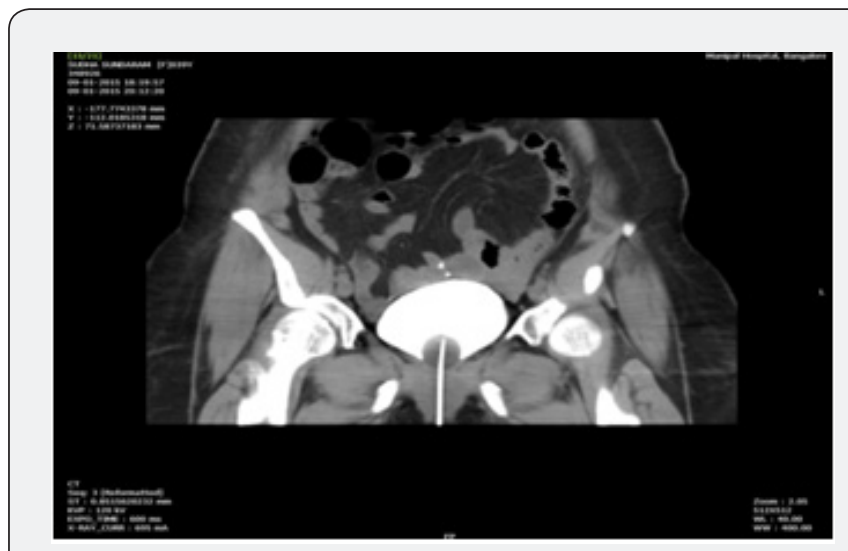

Figure 4: CT cystography.

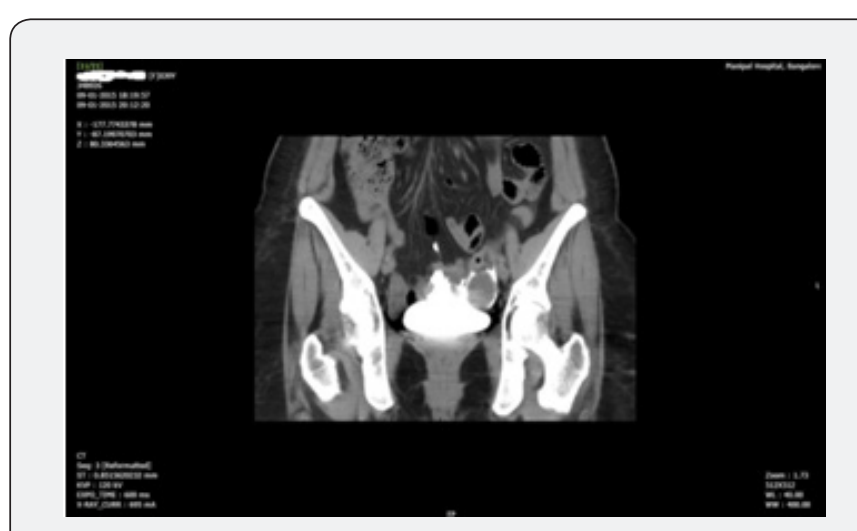

Figure 5:CT cystography defect in urinary bladder with extravasation of contrast outside the urinary bladder.

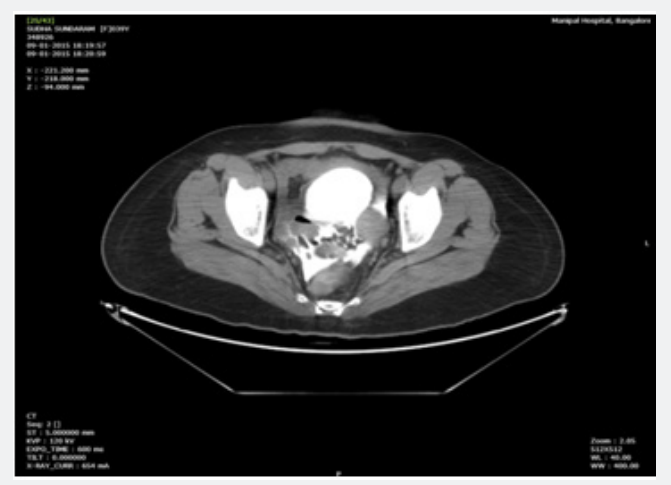

Figure 6: Defect in the posterior wall of urinary bladder with extravasation of contrast outside the urinary bladder.

\section{Discussion}

Spontaneous urinary bladder rupture is a very rare emergency [1,2] although an over distended urinary bladder with unnoticed events such as the individual under the influence of alcohol may cause urinary bladder rupture. Urinary bladder is the most common organ injured during gynecological procedures including cesarean delivery [3]. Other conditions predispose the patient to urinary bladder injury are intra-abdominal diseases such as endometriosis or pelvic inflammatory disease, and presence of adhesions from previous surgery.

For urinary bladder rupture intravesical pressure of more than $300 \mathrm{~cm}$ of water is required. Underlying pathology that weaken the bladder wall is present mostly in the form of previous bladder injury by gynecological surgery, pelvic radiotherapy, bladder surgery and others pelvic surgery [4]. In our case, most probably the bladder was injured during cesarean delivery 12 years back.

The classical symptoms of bladder rupture are sudden onset of abdominal pain with impaired micturition and ascites [5]. Other common symptoms include nausea and vomiting, difficulty or inability to void, hematuria, dysuria [1]. 
Most of the patients with urinary ascites have elevation in the urea and creatinine mimicking renal failure as well as hyperkalemia and hyponatraemia because the peritoneal membrane acts as a filter and absorbs urea, creatinine and also allows the exchange of electrolytes [6,7].

Urea and creatinine levels measurement in ascites fluid and plasma is a simple and non-invasive diagnostic test to diagnose urinary ascites [8]. In presence of acute renal failure, CT cystography is difficult to perform but beneficial for the detection of bladder perforation [1].

For spontaneous bladder rupture, the mortality rate is as high as $25 \%$ when associated with a delay in diagnosis. This mortality rate can be reduced by appropriate early diagnosis and prompt surgical intervention [5].

\section{Conclusion}

In case of sudden onset ascites, abdominal pain, oliguria and biochemical features of acute renal failure, urinary bladder rupture should be considered in differential diagnosis. The clue to the diagnosis of urinary ascites is markedly elevated ascitic fluid urea and creatinine levels despite near normal serum urea and creatinine level. Improvement of ascites and ascitic fluid creatinine level after urinary catheterization also give clue for diagnosis of urinary ascites. Urgent diagnosis and surgical repair are associated with good prognosis.

\section{References}

1. Izumi J, Hirano H, Kato T, Ito T, Kinoshita K, et al. (2012) CT findings of spontaneous intraperitoneal rupture of the urinary bladder: two case reports. Jpn J Radiol 30(3): 284-287.

2. Bastable JR, De Jode LR, Warren RP (1959) Spontaneous rupture of the bladder. Br J Urol 31(1): 78-86.

3. Williams JC, Heaney JA, Young W (1994) Respiratory distress following cesarean section: Cryptic presentation of bladder injury. Urology 44(3): 441-443.

4. Arun KG, Salahauddin, Leela V, Noel J, Venkatesh K, et al. (2008) Intraperitoneal bladder rupture mimicking acute renal failure. Indian J Nephrol 18(1): 26-27.

5. Ketata S, Boulaire JL, Al-Ahdab N, Bargain A, Damamme A (2007) Spontaneous intraperitoneal perforation of the bladder: a late complication of radiation therapy for prostate cancer. Clin Genitourin Cancer 5(4): 287-290.

6. Tai CK, Li SK, Hou SM, Fan CW (2008) Bladder injury mimicking acute renal failure after cesarean section. Surg Laparosc Endosc Percutan Tech 18(3): 301-303.

7. Vilos GA, Haebe J, Crumley TL, Maruncic MA, King JH, et al. (2001) Serum biochemical changes after laparoscopy may be indicators of bladder injury. J Am Assoc Gynecol Laparosc 8(2): 285-290.

8. Snauwaert C, Geerts A, Colle I, Van Vlierberghe H (2012) Ascites: not always the usual suspects. Acta Gastroenterol Belg 75(1): 45-48.

\section{Your next submission with Juniper Publishers will reach you the below assets}

- Quality Editorial service

- Swift Peer Review

- Reprints availability

- E-prints Service

- Manuscript Podcast for convenient understanding

- Global attainment for your research

- Manuscript accessibility in different formats

( Pdf, E-pub, Full Text, Audio)

- Unceasing customer service

Track the below URL for one-step submission https://juniperpublishers.com/online-submission.php 